\title{
The LysR-type PcaQ protein regulates expression of a protocatechuate-inducible ABC-type transport system in Sinorhizobium meliloti
}

\begin{abstract}
Correspondence
Turlough M. Finan

finan@mcmaster.ca
\end{abstract}

Received 18 April 2011

Revised 11 June 2011

Accepted 20 June 2011

\author{
Allyson M. MacLean, Wilfried Haerty, G. Brian Golding and \\ Turlough M. Finan
}

\author{
Center for Environmental Genomics, Department of Biology, McMaster University, Hamilton \\ L8S 4K1, Canada
}

\begin{abstract}
The LysR protein $\mathrm{PcaO}$ regulates the expression of genes encoding products relevant to the degradation of the aromatic acid protocatechuate (3,4-dihydroxybenzoate), and we have previously defined a PcaO DNA-binding site located upstream of the target $p c a D C H G B$ operon in Sinorhizobium meliloti. In this work, we show that $\mathrm{PcaQ}$ also regulates the expression of the $S$. meliloti smb20568-smb20787-smb20786-smb20785-smb20784 gene cluster, which is predicted to encode an $\mathrm{ABC}$ transport system. $\mathrm{ABC}$ transport systems have not been shown before to transport protocatechuate, and we have designated this gene cluster pcaMNVWX. The transcriptional start site of $p c a M$ was mapped, and the predicted $P c a Q D N A$-binding site was located at -73 to -58 relative to this site. Results from electrophoretic mobility shift assays with purified PcaQ and from expression assays indicated that PcaO activates expression of the transport system in the presence of protocatechuate. To investigate this transport system further, we generated a pcaM deletion mutant (predicted to encode the substrate-binding protein) and introduced a polar insertion mutation into $p c a N$, a gene that is predicted to encode a permease. These mutants grew poorly on protocatechuate, presumably because they fail to transport protocatechuate. Genome analyses revealed PcaQ-like DNA-binding sites encoded upstream of $\mathrm{ABC}$ transport systems in other members of the $\alpha$-proteobacteria, and thus it appears likely that these systems are involved in the uptake of protocatechuate.
\end{abstract}

\section{INTRODUCTION}

The $\beta$-ketoadipate pathway is a peripheral metabolic pathway through which a variety of lignin-derived and anthropogenic aromatic substrates can be degraded following their conversion to one of two common intermediates, either protocatechuate or catechol (Harwood \& Parales, 1996). The Gram-negative legume microsymbiont Sinorhizobium meliloti encodes the protocatechuate branch of the $\beta$-ketoadipate pathway on the pSymB megaplasmid, and $S$. meliloti can utilize protocatechuate as a sole source of carbon (MacLean et al., 2006). Protocatechuate catabolic genes are organized into two operons ( $p c a D C H G B$ and pcaIJF), whose expression is regulated by the transcriptional regulators PcaQ and PcaR, respectively (MacLean et al., 2006, 2008). While systems involved in the active transport of aromatic acids such as protocatechuate have been described in many species, including Pseudomonas putida (Harwood et al., 1994;

Abbreviations: $\alpha$ CTD-RNAP, RNA polymerase alpha subunit; Gm, gentamicin; $\mathrm{Gm}^{\text {r }}$, Gm-resistant; Gms, Gm-sensitive; MFS, major facilitator superfamily; Nm, neomycin; Rif, rifampicin; RNAP, RNA polymerase; Sm, streptomycin; Sp, spectinomycin; Spr', Sp-resistant; sucrose', sucroseresistant.
Nichols \& Harwood, 1997), a protocatechuate transport system has yet to be identified in S. meliloti or any other member of the $\alpha$-proteobacteria. Furthermore, S. meliloti appears to lack protein homologues of the PcaK major facilitator superfamily of aromatic acid transport proteins (Collier et al., 1997; Williams \& Shaw 1997; D’Argenio et al., 1999; Ledger et al., 2009).

PcaQ is a member of the LysR family of regulatory proteins, and requires the co-effectors $\beta$-carboxy-cis,cismuconate and $\gamma$-carboxymuconolactone to induce expression of pcaDCHGB in Agrobacterium tumefaciens and $S$. meliloti (Parke, 1993, 1996; MacLean et al., 2006, 2008). LysR-type transcriptional regulators participate in the regulation of a wide variety of physiological processes, including carbon and nitrogen metabolism, aromatic and amino acid degradation, virulence in plant and animal pathogens, quorum sensing, and the oxidative stress response (Maddocks \& Oyston, 2008). As a general model, LysR proteins activate gene expression via interaction with a recognition (or repression) binding site that is positioned upstream of a target promoter and contains the primary binding determinant that is necessary for an interaction of 
high affinity (Parsek et al., 1992; Akakura \& Winans, 2002). In the presence of a co-effector, the regulator interacts with a downstream activation binding site that is required for the induction of gene expression (Huang \& Schell, 1991; Parsek et al., 1992; Bundy et al., 2002). To activate transcription, many LysR proteins have been demonstrated to require direct interaction with the C-terminal domain of the RNA polymerase (RNAP) alpha subunit ( $\alpha$ CTDRNAP) (Tao et al., 1993; Chugani et al., 1997; McFall et al., 1998; Fritsch et al., 2000; Park et al., 2002). In 1992, Goethals and co-workers identified a LysR DNA-binding motif $\left(\mathrm{TN}_{11} \mathrm{~A}\right)$ present in the majority of binding sites (Goethals et al., 1992); however, the in silico prediction of LysR regulatory binding sequences is compromised by the prevalence of this motif within AT-rich intergenic regions.

We have previously described a PcaQ DNA-binding motif that is located upstream of $p c a D$ in $S$. meliloti and is conserved in related rhizobia such as A. tumefaciens (MacLean et al., 2008). In this work, we identify putative PcaQ DNA-binding sites positioned upstream of genes in members of the classes $\alpha$-, $\beta$ - and $\gamma$-Proteobacteria. In $11 \alpha$ proteobacteria, PcaQ DNA-binding sites were located upstream of genes encoding ABC-type transport systems, and in the case of $S$. meliloti, we demonstrate that $\mathrm{PcaQ}$ regulates the expression of these $\mathrm{ABC}$ transport genes and that the gene encoding the solute-binding protein is required for growth on protocatechuate as carbon source.

\section{METHODS}

Bacterial strains and growth conditions. All plasmids and bacterial strains used throughout this study are described in Table 1. Escherichia coli strains were grown aerobically in Luria-Bertani (LB) broth at $37^{\circ} \mathrm{C}$. S. meliloti strains were grown aerobically at $30{ }^{\circ} \mathrm{C}$ in LB broth supplemented with $2.5 \mathrm{mM} \mathrm{MgSO}_{4}$ and $2.5 \mathrm{mM}$ $\mathrm{CaCl}_{2}$ (LBmc). M9 minimal medium (Difco) salts were supplemented with $1.0 \mathrm{mM} \mathrm{MgSO}_{4}, 0.25 \mathrm{mM} \mathrm{CaCl}_{2}, 1 \mu \mathrm{g}$ D-biotin $\mathrm{ml}^{-1}$ and $10 \mathrm{ng}$ $\mathrm{CoCl}_{2} \mathrm{ml}^{-1}$. Filter-sterilized $0.5 \%(\mathrm{v} / \mathrm{v})$ glycerol, $10 \mathrm{mM}$ succinate or $5 \mathrm{mM}$ protocatechuate (Sigma-Aldrich) was added as indicated to M9 minimal medium as a source of carbon. For E. coli strains, the following antibiotic concentrations were used $\left(\mu \mathrm{g} \mathrm{ml}{ }^{-1}\right)$ : chloramphenicol $(\mathrm{Cm}), 20$; kanamycin $(\mathrm{Kn}), 10$; gentamicin $(\mathrm{Gm}), 10$. For S. meliloti, the concentrations used were: streptomycin (Sm), 200; spectinomycin $(\mathrm{Sp}), 200$; neomycin $(\mathrm{Nm}), 200$; gentamicin $(\mathrm{Gm}), 60$; rifampicin (Rif), 20.

Computational analyses. A consensus PcaQ DNA-binding site was generated using conserved sequences upstream of pcaD in $A$. tumefaciens C58 (Atu4542), Mesorhizobium loti MAFF303099 (mlr7206), Rhizobium etli CFN42 (RHE_PE00059), R. leguminosarum bv. viciae 3841 (pRL110089), S. meliloti Rm1021 (SMb20579) and Sinorhizobium medicae WSM419 (Smed_4206). The fully sequenced genomes and plasmids of all $\alpha$-proteobacteria [217 genome and plasmid sequences, available as of December 2008; National Center for Biotechnology Information (NCBI) Genome Database], and selected members of the $\gamma$-proteobacteria [Pseudomonas (11 sequences)] and $\beta$-proteobacteria [Burkholderia and Ralstonia (85 sequences)], were scanned on both the positive and negative strands for the consensus PcaQ DNA-binding motif $\left(5^{\prime}\right.$-ATAAYY- $(\mathrm{N})_{x^{-}}$ RRTTAW-3', where $x=3,4$ or 5), while allowing for one mismatch within the regulatory site. The output data were screened manually, and putative binding sites positioned upstream of genes encoding aromatic acid catabolic enzymes and/or LysR-type regulators were extracted for further analysis. The sequence logo was generated by WebLogo (Crooks et al., 2004) using as input all PcaQ DNA-binding sites identified upstream of target genes in members of the $\alpha$ - and $\gamma$ proteobacteria, as shown in Fig. 1 and listed in Table 2. Predicted binding sites in $\beta$-proteobacteria were excluded from the analysis due to a $1 \mathrm{bp}$ deletion within the motif.

Construction of $\boldsymbol{S}$. meliloti transporter mutants. We targeted the gene encoding a periplasmic solute-binding protein $(\mathrm{smb20568)}$ for disruption via introduction of an in-frame deletion. Primers ( $5^{\prime}-$ TCGTCTAGAACGTGACGATGGTTCTGG- $3^{\prime}$ and $5^{\prime}$-TCTAAGCTTCGATCGTCATCAGCACCTG-3') were used to amplify a $1965 \mathrm{bp}$ fragment, which was cloned into pUCP30T via $\mathrm{XbaI}$ and HindIII, yielding pTH1948. A PstI digestion was performed upon pTH1948 to generate a $687 \mathrm{bp}$ deletion within $s m b 20568$ (in-frame deletion of 229 aa), to create plasmid pTH1949. The S. meliloti insert in pTH1949 (with the 687 bp deletion) was then subcloned into the suicide vector pJQ200 (Quandt \& Hynes, 1993) in the following manner. pTH1949 was digested with $\mathrm{XbaI}$ and HindIII to liberate the $S$. meliloti insert DNA from the pUCP30T backbone. Klenow fragment of DNA polymerase I (New England Biolabs) was added to digested DNA to yield blunt-ended DNA fragments, which were resolved and purified from the agarose gel and cloned into the suicide vector $\mathrm{PJQ} 200 \mathrm{uc}-1$ via SmaI to create pTH1959. This plasmid was transferred into wild-type $S$. meliloti strain RmP110, and single crossover recombinants were selected by plating on LB agar supplemented with $\mathrm{Gm}$. A single purified Gmresistant $\left(\mathrm{Gm}^{\mathrm{r}}\right)$ transconjugant was grown overnight in LBmc in the absence of antibiotic selection. Aliquots of the overnight culture were plated on LB agar in the presence of $5 \%$ sucrose to select for cells in which the integrated plasmid had recombined out of the genome. Sucrose-resistant (sucrose ${ }^{\mathrm{r}}$ ) colonies were patched on $\mathrm{Gm}$ to confirm the loss of the pJQ200 derivative plasmid. Ten sucrose ${ }^{r}$ and Gmsensitive $\left(\mathrm{Gm}^{\mathrm{s}}\right)$ strains were screened via whole-cell PCR amplification of $s m b 20568$ for the presence of a 687 bp deletion; of these, five strains yielded products consistent with the incorporation of a deletion within this gene. Sequencing reactions were performed upon genomic DNA to confirm the genotype of each strain using primers complementary to a sequence external to the region cloned into pJQ200. One of the strains was selected for use in this study and was designated RmP1710.

A second transporter mutant strain was constructed through the insertion of an antibiotic cassette into smb20787. An Sm/Sp-resistance cassette was cloned into a SacII site within $s m b 20787$ as follows. Primers (5'-ATGCGGCCGCTGCATCGTTGGTTTGG-3' and $5^{\prime}$ ATGCGGCCGCAATAGCCGGTGACG-3') were used to PCR-amplify a sequence spanning a SacI site located 187 bp downstream of the predicted translational start site of $s m b 20787$. The $1149 \mathrm{bp}$ amplified product was cloned into plasmid pTH1883 via a NotI restriction site, yielding pTH1908. pTH1883 is a derivative of pVO155 (Oke \& Long, 1999) in which the reporter gene gusA has been deleted; this plasmid was selected because it is unable to replicate in $S$. meliloti and thus may be used as a means of recombining the antibiotic cassette into the $S$. meliloti genome. The $\mathrm{Sm} / \mathrm{Sp}$-resistance cassette from $\mathrm{pHP} 45 \Omega$ (Prentki \& Krisch, 1984) was PCR-amplified and cloned into pTH1908 following digestion with SacII to create pTH1917. This plasmid was transferred by conjugation into the Rif-resistant $S$. meliloti strain Rm5000; recombinants were selected by plating on LB agar supplemented with Rif and Sp. Transconjugants were patched on LB agar plus Nm to screen for loss of pTH1917.

Southern hybridization was performed to confirm integration of the $\Omega$ cassette within smb20787 as follows. Briefly, primers $\left(5^{\prime}-\right.$ CGAGATCGAGCGAGAGTACCAGC-3' and 5'-GGAGAACGTGACGATGGTTCTGG-3') were used to amplify a probe corresponding to smb20787. SalI digests were performed upon genomic DNA 
Table 1. Strains and plasmids used in this study

Abbreviations: $A \mathrm{mp}^{\mathrm{r}}$, ampicillin resistant; $\mathrm{Kn}^{\mathrm{r}}$, kanamycin resistant; $\mathrm{Sm}^{\mathrm{r}}$, streptomycin resistant; $\mathrm{Tc}^{\mathrm{r}}$, tetracycline resistant.

\begin{tabular}{|c|c|c|}
\hline Strain or plasmid & Relevant characteristics & Source or reference \\
\hline \multicolumn{3}{|l|}{ S. meliloti strains } \\
\hline $\mathrm{RmP} 110$ & Rm1021 with wild-type $p s t C ; \mathrm{Sm}^{\mathrm{r}}$ & Yuan et al. (2006) \\
\hline $\mathrm{RmP} 1676$ & $\mathrm{RmP110} p c a Q:: \Omega ; \mathrm{Sm}^{\mathrm{r}}, \mathrm{Sp}^{\mathrm{r}}$ & MacLean et al. (2008) \\
\hline $\mathrm{RmP} 1710$ & RmP110 $\Delta p c a M, 687$ bp in-frame deletion created via pTH1959; $\mathrm{Sm}^{\mathrm{r}}, \mathrm{Gm}^{\mathrm{s}}$, sucrose $\mathrm{e}^{\mathrm{r}}$ & This study \\
\hline $\mathrm{RmP} 1712$ & $\operatorname{RmP110}$ pcaN: $: \Omega ; \mathrm{Sm}^{\mathrm{r}}, \mathrm{Sp}^{\mathrm{r}}$ & This study \\
\hline RmP1811 & $\mathrm{RmP110} p c a Q:: \Omega$ pcaM::gfp $p^{+} / l a c Z ; \mathrm{Sm}^{\mathrm{r}}, \mathrm{Sp}^{\mathrm{r}}, \mathrm{Gm}^{\mathrm{r}}$ & This study \\
\hline \multicolumn{3}{|l|}{ Plasmids } \\
\hline pFL1131 & $\begin{array}{l}2619 \text { bp fragment extending from within smb20571 to pcaM (1581 256-1 } 583875 \mathrm{nt} \text {; } \\
\text { pSymB) in pTH1522; } \mathrm{Gm}^{\mathrm{r}}\end{array}$ & Cowie et al. (2006) \\
\hline $\mathrm{pHP} 45 \Omega$ & pBR322 derivative with $\Omega$ element; $\mathrm{Amp}^{\mathrm{r}}, \mathrm{Sp}^{\mathrm{r}}, \mathrm{Sm}^{\mathrm{r}}$ & Prentki \& Krisch (1984) \\
\hline pJQ200 uc1 & Suicide vector with $\operatorname{sacB}$ to select for plasmid excision; $\mathrm{Gm}^{\mathrm{r}}$ & Quandt \& Hynes (1993) \\
\hline pOT1 & Broad-host-range $g f p u v$ transcription reporter; $\mathrm{Gm}^{\mathrm{r}}$ & Allaway et al. (2001) \\
\hline pUCP30T & Cloning vector; $\mathrm{Gm}^{\mathrm{r}}$ & $\begin{array}{l}\text { GenBank accession no. } \\
\text { U33752 }\end{array}$ \\
\hline рTH1227 & Broad-host-range derivative of pFus1 with $P_{\text {tac }}$ promoter inserted upstream of $g u s A ; \mathrm{Tc}^{\mathrm{r}}$ & $\begin{array}{l}\text { J. Cheng and T. M. Finan, } \\
\text { unpublished results }\end{array}$ \\
\hline pTH1705 & Derivative of pTH1522; transcription fusion reporter plasmid; $\mathrm{Gm}^{\mathrm{r}}$ & Cowie et al. (2006) \\
\hline pTH1883 & pVO155 derivative lacking gusA, suicide plasmid in S. meliloti; $\mathrm{Amp}^{\mathrm{r}}, \mathrm{Kn}^{\mathrm{r}}$ & Laboratory collection \\
\hline pTH1908 & 1149 bp PCR-amplified fragment spanning $p c a N$ into pTH1883 via NotI; $\mathrm{Amp}^{\mathrm{r}}, \mathrm{Kn}^{\mathrm{r}}$ & This study \\
\hline рTH1917 & $\Omega S m / \mathrm{Sp}^{\mathrm{r}}$ into pTH1908 via SacII; $\mathrm{Amp}^{\mathrm{r}}, \mathrm{Kn}^{\mathrm{r}}, \mathrm{Sm}^{\mathrm{r}}, \mathrm{Sp}^{\mathrm{r}}$ & This study \\
\hline рTH1948 & 1965 bp PCR-amplified fragment spanning pcaM into pUCP30T via XbaI/HindIII; Gm ${ }^{\mathrm{r}}$ & This study \\
\hline рTH1949 & pTH1948 with a 687 bp deletion via PstI; $\mathrm{Gm}^{\mathrm{r}}$ & This study \\
\hline рTH1959 & XbaI/HindIII insert from pTH1949 into pJQ200 via SmaI; Gm ${ }^{\mathrm{r}}$ & This study \\
\hline pTH1960 & $\begin{array}{l}1139 \text { bp PCR-amplified fragment spanning } p c a I \text { and } p c a R \text { intergenic region into } \\
\text { pTH1705 via BglII/KpnI; } \mathrm{Gm}^{\mathrm{r}}\end{array}$ & This study \\
\hline рTH2410 & $\begin{array}{l}242 \text { bp PCR product encompassing pcaM-smb20569 intergenic region into pUCP30T } \\
\text { via XbaI; } \mathrm{Gm}^{\text {r }}\end{array}$ & This study \\
\hline pTH2414 & 246 bp PCR-amplified insert from pTH2410 into pOT1 (pcaM::gfpuv); $\mathrm{Gm}^{\mathrm{r}}$ & This study \\
\hline рТН 2424 & $\mathrm{~A}(-62) \mathrm{G}$ site-directed mutation into pOT1; $\mathrm{Gm}^{\mathrm{r}}$ & This study \\
\hline рTH 2425 & $\mathrm{~A}(-62) \mathrm{C}$ site-directed mutation into pOT1; $\mathrm{Gm}^{\mathrm{r}}$ & This study \\
\hline рTH2426 & $\mathrm{C}(-69)$ A site-directed mutation into pOT1; $\mathrm{Gm}^{\mathrm{r}}$ & This study \\
\hline pTH2427 & $\mathrm{A}(-59) \mathrm{G}$ site-directed mutation into pOT1; $\mathrm{Gm}^{\mathrm{r}}$ & This study \\
\hline рTH2428 & $\mathrm{T}(-61) \mathrm{G}$ site-directed mutation into pOT1; $\mathrm{Gm}^{\mathrm{r}}$ & This study \\
\hline pTH2432 & $\mathrm{A}(-73) \mathrm{G}$ site-directed mutation into pOT1; $\mathrm{Gm}^{\mathrm{r}}$ & This study \\
\hline pTH2433 & $\mathrm{A}(-71) \mathrm{G}$ site-directed mutation into pOT1; $\mathrm{Gm}^{\mathrm{r}}$ & This study \\
\hline рTH2454 & PCR-amplified pcaQ-his into pTH1227 via BglII/EcoRI; Tc ${ }^{\mathrm{r}}$ & This study \\
\hline
\end{tabular}

isolated from two $\mathrm{Sp}$-resistant $\left(\mathrm{Sp}^{\mathrm{r}}\right)$ and $\mathrm{Nm}$-sensitive $\left(\mathrm{Nm}^{\mathrm{s}}\right)$ colonies and wild-type strain RmP110. In both putative smb20787:: $\Omega$ mutants, an $\sim 2 \mathrm{~kb}$ shift (compared with wild-type) in one of the three hybridized SalI fragments was noted, consistent with the incorporation of the $2.1 \mathrm{~kb}$ cassette into the SacII site and excision of pTH1917. The smb20787:: $\Omega$ allele was transferred from one of the Rm5000 mutants into RmP110 through selection of $\mathrm{Sp}^{\mathrm{r}}$ transductants. This strain (RmP110 smb20787:: $\Omega$ ) was designated RmP1712.
Construction of reporter plasmids and plasmid pTH2454. The smb20568-smb20569 intergenic region of S. meliloti was PCR-

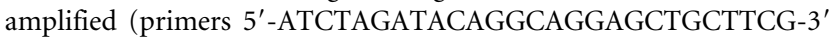
and $5^{\prime}$-ATTCTGCAGCAGAATGATCCTTCTCATATTTCCT- $3^{\prime}$ ) and cloned into the broad-host-range plasmid pOT1 (Allaway et al., 2001) via $X b a \mathrm{I}$ and PstI to create a transcriptional fusion with the promoterless reporter gene $g f p$ (smb20568::gfp, i.e. $p c a M:: g f p)$. Plasmids were mobilized into the recipient $S$. meliloti wild-type strain

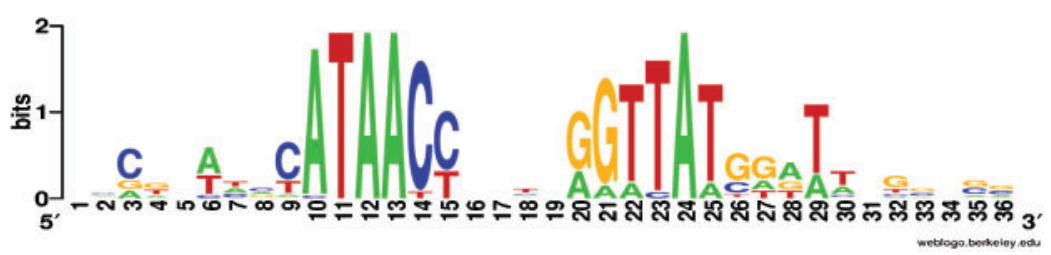

Fig. 1. Sequence logo representing $\mathrm{PcaO}$ DNA-binding sites identified in the $\alpha$ - and $\gamma$ proteobacteria. The sequence logo was created using WebLogo (Crooks et al., 2004). 
Table 2. Description of putative PcaQ-binding motifs in proteobacteria

List of predicted PcaQ DNA-binding sites identified in the $\alpha$-, $\beta$ - and $\gamma$-proteobacteria. Gene annotations are as assigned by the relevant genomesequencing projects. Nucleotides in bold type are substitutions or deletions that likely reduce the level of gene expression under inducing conditions.

\begin{tabular}{|c|c|c|c|c|}
\hline Species & Class $^{*}$ & Nucleotide sequence & Gene annotation & Locus \\
\hline Azorhizobium caulinodans ORS 571 & $\alpha$ & ATAA CCCTCAGG TTAT & pcaDHGB & AZC_1444 \\
\hline A. tumefaciens $\mathrm{C} 58$ & $\alpha$ & ATAA TCCACAGG TTAT & pcaDCHGB & Atu 4542 \\
\hline B. abortus S19 & $\alpha$ & ATAA CTGTTCGG ATAT & ABC-type transporter & BAbS19_II05550 \\
\hline Brucella canis ATCC 23365 & $\alpha$ & ATAA CCTGTGAG TTAT & pcaDCGB & BCAN_B0644 \\
\hline B. canis ATCC 23365 & $\alpha$ & ATAA CTGTTCGG ATAT & ABC-type transporter & BCAN_B0648 \\
\hline B. melitensis $16 \mathrm{M}$ & $\alpha$ & ATAA CTGTTCGG ATAT & ABC-type transporter & BMEII0633 \\
\hline Brucella ovis ATCC 25840 & $\alpha$ & ATAA CCTGTGAG TTAT & pcaCG & BOV_A0606 \\
\hline B. ovis ATCC 25840 & $\alpha$ & ATAA CTGTTCGG ATAT & ABC-type transporter & BOV_A0610 \\
\hline Brucella suis 1330 & $\alpha$ & ATAA CCTGTGAG TTAT & pcaDCHGB & BRA0643 \\
\hline B. suis 1330 & $\alpha$ & ATAA CTGTTCGG ATAT & ABC-type transporter & BRA0648 \\
\hline M. loti MAFF303099 & $\alpha$ & ATAA CCCCCGAG TTAA & pcaDCHGBpobA & mlr7206 \\
\hline R. etli CFN42 & $\alpha$ & ATAA CCTCGGAG TTAT & pcaDCHGB & RHE_PE00059 \\
\hline R. etli CFN42 & $\alpha$ & ATAA CCGGCAAA TCAT & ABC-type transporter & RHE_CH03445 \\
\hline R. leguminosarum bv. viciae 3841 & $\alpha$ & ATAA TTGTACAG TTAT & ABC-type transporter & RL3906 \\
\hline R. leguminosarum bv. viciae 3841 & $\alpha$ & ATAA CTCCACGG TTAT & pcaDCHGB & pRL110089 \\
\hline R. leguminosarum bv. trifolii WSM2304 & $\alpha$ & ATAA CTCCCAGG TTAT & pcaDCHGB & Rleg2_5939 \\
\hline S. meliloti $\mathrm{Rm} 1021$ & $\alpha$ & ATAA CCGGGGGA TTAT & ABC-type transporter & $s m b 20568$ \\
\hline S. meliloti Rm1021 & $\alpha$ & ATAA CCTCCTGG TTAA & pcaDCHGB & $s m b 20579$ \\
\hline S. medicae WSM419 & $\alpha$ & ATAA CCGGGGAA TTAT & ABC-type transporter & Smed_4217 \\
\hline S. medicae WSM419 & $\alpha$ & ATAA CTCCCTGG TTAA & pcaDCHGB & Smed_4206 \\
\hline Burkholderia mallei NCTC 10229 & $\beta$ & ATAA CGGTTAG TTAT & pcaHG & BMA10229_0245 \\
\hline Burkholderia multivorans ATCC 17616 & $\beta$ & ATAA CCACCCG TTAT & pcaHG & BMULJ_04089 \\
\hline Pseudomonas fluorescens Pf- 5 & $\gamma$ & ATAA CCATTTGG TTAT & pcaHG & PFL_5396 \\
\hline P. putida W619 & $\gamma$ & ATAA CCATTTGG TTAA & pcaHG & PputW619_0780 \\
\hline Pseudomonas stutzeri A1501 & $\gamma$ & ATAA CCCCTGGG TTAT & pcaHG & PST_1249 \\
\hline $\begin{array}{l}\text { Pseudomonas syringae pv. phaseolicola } \\
1448 \mathrm{~A}\end{array}$ & $\gamma$ & ATAA CCATTTGG TTAT & pcaHGKBC & PSPPH_2096 \\
\hline P. syringae pv. tomato str. DC 3000 & $\gamma$ & ATAA CCAATTGG TTAT & pcaHGKBC & PSPTO_2338 \\
\hline
\end{tabular}

${ }^{*}$ Proteobacterial class.

RmP110 and PcaQ-minus strain RmP1676 via triparental conjugation with MT616 (pRK600) (Finan et al., 1986).

Plasmid pTH1979 contains pcaQ cloned into the expression vector pET-21a (Novagen) to create a translational fusion with a hexahistidine tag at the $\mathrm{N}$ terminus of the $S$. meliloti protein (MacLean et al., 2008). This plasmid was used as template DNA for the PCR amplification of pcaQ-his using the primers $5^{\prime}$ GTGAGATCTAAGAAGGAGATATACATATGATCGAC-3' and ' ${ }^{\prime}$ -
AGAATTCGTTAGCAGCCGGATCTCAGTG-3' into the broadhost-range replicating plasmid pTH1227 via BglII and EcoRI to create plasmid pTH2454, in which pcaQ-his is expressed from the $\mathrm{P}_{t a c}$ promoter. After sequencing (to confirm the absence of mutations within the coding sequence), the plasmid was transferred via conjugation into $S$. meliloti strain RmP1811 (RmP110 pcaQ:: $\Omega$ smb20568::gfp + /lacZ), in which expression of $p c a Q$ has been disrupted through the integration of an $\mathrm{Sp} / \mathrm{Sm}$ antibiotic-resistance cassette. RmP1811 also contains a transcriptional fusion (smb20568::gfp + /lacZ) created through the 
integration of plasmid pFL1131 (Cowie et al., 2006), which allows expression of $s m b 20568$ to be monitored via $\beta$-galactosidase assays.

Site-directed mutagenesis. To modify the PcaQ DNA-binding site located upstream of $s m b 20568$, plasmid pTH2410 was used as a template for mutagenesis reactions and was constructed as follows. Primers (5'-ATCTAGATACAGGCAGGAGCTGCTTCG- ${ }^{\prime}$ and $5^{\prime}$ ATCTAGAGCCAGAATGATCCTTCTCATATTTCCT- $3^{\prime}$ ) were used to PCR-amplify the smb20568-smb20569 intergenic region, which was cloned into pUCP30T (GenBank accession no. U33752) via XbaI. Site-directed mutagenesis reactions were performed using Platinum Pfx DNA polymerase (Invitrogen) according to the supplier's protocol. After amplification, $20 \mathrm{U} D p n \mathrm{I}$ (New England Biolabs) was added directly to the reaction mixture, which was incubated at $37{ }^{\circ} \mathrm{C}$ for $2 \mathrm{~h}$. Plasmid DNA was purified using QIAquick spin columns (Qiagen) and transformed into chemically competent $E$. coli DH $5 \alpha$. Transformants were selected via Gm resistance, and plasmids were sequenced to confirm the presence of site-directed mutations by Mobix Lab (McMaster University, Hamilton, ON, Canada). For the purpose of constructing $g f p$ reporter fusions, the pUCP30T derivative plasmids (each carrying a site-directed mutation) were used as template DNA for the PCR amplification of the smb20568-smb20569 intergenic region using the same primers as those described for the amplification of the wild-type regulatory region.

$\boldsymbol{\beta}$-Galactosidase and GFP assays. A transcriptional fusion between $S$. meliloti pcaI and the reporter gene lacZ was created as follows. The intergenic region between $p c a I$ and $p c a R$ was amplified using primers (5'-ATCAGATCTGAGTTCGTCGACGATCTCC-3' and $5^{\prime}$-TAGGTACCCAGGTTGATCGACATCACC-3'). The amplified product was cloned into the reporter plasmid pTH1705 (Cowie et al., 2006) via BglII and KpnI to create pcaI::gfp+ /lacZ. The resulting plasmid (pTH1960) is unable to replicate in S. meliloti; however, it carries an $\sim 1 \mathrm{~kb}$ region that is homologous to the $S$. meliloti pcaI-R intergenic region. pTH1960 was introduced into $\mathrm{RmP110}, \mathrm{RmP} 1710$ and $\mathrm{RmP} 1712$ through triparental conjugation with the E. coli helper strain MT616 (pRK600) (Finan et al., 1986). Transconjugants in which pTH1960 had recombined into the pSymB megaplasmid were isolated by demanding growth on LB agar plus Sm and $\mathrm{Gm}$.

$\beta$-Galactosidase enzyme assays were performed as previously described (MacLean et al., 2006) upon S. meliloti strains subcultured into M9 minimal medium with glycerol and/or protocatechuate as carbon sources. Gfp fluorescence was assayed as previously described (MacLean, et al., 2008). Relative fluorescence was determined by dividing the emission output of each sample by its respective $\mathrm{OD}_{600}$.

Primer extension and electrophoretic mobility shift assays. Total RNA was isolated from an S. meliloti RmP110 culture grown aerobically at $30{ }^{\circ} \mathrm{C}$ in $\mathrm{LBmc} \pm 5 \mathrm{mM}$ protocatechuate to $\mathrm{OD}_{600} 0.8$. RNA extraction was performed using a hot phenol method, as previously described (MacLellan et al., 2005). Approximately $60 \mu \mathrm{g}$ total RNA was used in each extension reaction, as previously described (MacLellan et al., 2005). Two primers were used to yield extension products $\left(5^{\prime}\right.$-CCAGAATGATCCTTCTCATATTTCCTCC$3^{\prime}$ and $5^{\prime}$-CGACGACTCCGACCTTGATCGTATCC-3'). Sequenase Version 2.0 DNA Sequencing kits (USB) were used for sequencing reactions, which were performed upon plasmid pFL1131. The same primers were used in both sequencing and primer extension reactions.

A 246 bp probe spanning the smb20568 (pcaM) and smb20569 intergenic region $(-149$ to +87 ; smb20568 transcriptional start site) was PCR-amplified using primers (5'-ATCTAGATACAGGCAGGAGCTGCTTCG-3' and 5'-ATTCTGCAGCAGAATGATCCTTCTCATATTTCCT- $3^{\prime}$ ). PCR products were purified using a polyacrylamide gel before labelling reactions were performed using $\left[\gamma^{32} \mathrm{P}\right] \mathrm{ATP}$ (Perkin Elmer) and T4 polynucleotide kinase. Assays were performed using purified PcaQ-His, as previously described (MacLean et al., 2008).

\section{RESULTS}

\section{Prediction of putative PcaQ-binding sites in proteobacteria}

A consensus PcaQ DNA-binding motif was generated using the experimentally characterized binding site upstream of pcaD in S. meliloti (MacLean et al., 2008) and conserved sites upstream of $p c a D$ in related rhizobia. Using the consensus sequence $\left(5^{\prime} \text {-ATAAYY-(N) }\right)_{x}$-RRTTAW- $3^{\prime}$, where $x=3,4$ or 5 ), we scanned the genomes of $313 \alpha-, \beta$ - (Burkholderia and Ralstonia) and $\gamma$-proteobacteria (Pseudomonas) for potential regulatory sites. The majority of genomes yielded between zero and three hits for putative PcaQ DNA-binding sites. The quality of putative PcaQ DNA-binding sites was assessed based upon the position of a mismatch (if present) within the predicted regulatory sequence, as compared with the consensus sequence, and the proximity of the predicted site to likely target genes (i.e. upstream of a gene annotated to encode a product involved in aromatic acid catabolism or a LysR-type protein). Using these criteria, we identified candidate PcaQ DNA-binding sites within the genomes of species from all three groups of proteobacteria (Fig. 1, Table $2)$. In the $\alpha$-proteobacteria, conserved binding sites were located upstream of $p c a D$ (encoding $\beta$-ketoadipate enollactone hydrolase), consistent with previous reports documenting the regulation of this gene by $\mathrm{PcaQ}$ in $S$. meliloti and A. tumefaciens (Parke, 1993; MacLean et al., 2006). In $\beta$ and $\gamma$-proteobacteria, PcaQ DNA-binding sites were positioned upstream of the operon $p c a H G$, encoding the $\beta$ and $\alpha$ subunits of protocatechuate 3,4-dioxygenase, which mediates the first step in the metabolism of protocatechuate, a ring cleavage of the aromatic acid through the incorporation of oxygen (Stanier \& Ingraham, 1954). Furthermore, we identified putative PcaQ DNA-binding sites located upstream of genes encoding ABC-type transport systems in 10 members of the $\alpha$-proteobacteria, including S. meliloti. Expression of one of these $\mathrm{ABC}$-type transport systems (encoded by smb20568-smb20784 in S. meliloti) has previously been shown to be upregulated by growth with protocatechuate (Mauchline et al., 2006). As we show herein that the smb20568-smb20784 gene cluster is required for growth with protocatechuate, we designate these genes pcaMNVWX. This transport gene cluster is located approximately $8 \mathrm{~kb}$ downstream of the $p c a D C H G B$ operon on the pSymB megaplasmid.

\section{Identification of the pcaM transcriptional start site}

We have determined that the intergenic region between $p c a M$ and $p c a N$ does not contain a promoter (MacLean, 2008), and the non-coding regions located between the remaining transport genes (ranging from 3 to 19 nt between each gene) are unlikely to include a promoter. Thus it is 
probable that expression of the entire transport gene cluster is dependent upon a promoter located upstream of pcaM (smb20568). A primer extension analysis was performed to identify the pcaM transcription start site as a means of further elucidating the regulation of this gene cluster.

Total RNA was isolated from wild-type S. meliloti strain $\mathrm{RmP} 110$ grown in the presence and absence of protocatechuate, and extension reactions were performed using two different primers. With both primers, at least two extension products were obtained using RNA isolated from $S$. meliloti grown with and without protocatechuate (Fig. 2a). The larger of the two extension products corresponds to a transcriptional start site located $29 \mathrm{nt}$ upstream of the predicted pcaM translational start codon. A greater product yield for this transcript was obtained using RNA isolated from cells grown with protocatechuate; this is consistent with an upregulation of pcaM expression in the presence of protocatechuate. The smaller extension product corresponds to a transcriptional start site located within the predicted coding sequence of pcaM and is likely due to the premature termination of the extended product. The predicted PcaQ DNA-binding site was located -73 to -58 upstream of the ATG translational start codon of pcaM (Fig. 2b), and we note that this relative position is comparable with that of the experimentally characterized binding site -72 to -57 upstream of $p c a D$ (MacLean et al., 2008).

\section{Expression of an ABC-type transport system is regulated by $\mathrm{Pca} Q$}

To determine whether PcaQ is required for the protocatechuate-inducible expression of the $S$. meliloti transport system, the regulatory region upstream of a gene ( $p c a M$ ) encoding the periplasmic solute-binding protein was cloned into the broad-host-range reporter plasmid pOT1, to generate a transcriptional fusion with the reporter gene $g f p$. Expression of pcaM::gfp (pTH2414) was induced greater than sixfold in wild-type cells cultured with protocatechuate, confirming that expression of this gene cluster is responsive to growth with the aromatic acid. In contrast, expression of the transporter gene was not induced in RmP1676 (RmP110 pcaQ:: $\Omega$ ), indicating that the LysR-type regulator PcaQ is required for the upregulation of pcaM expression (Table 3). As a control, we included pcaD::gfp (pTH2276), and observed that $p c a D$ expression was not upregulated in RmP1676, consistent with the results of previous studies (MacLean et al., 2006, 2008). Furthermore, we observed that expression of pcaM in a pcaR mutant (RmP110 pcaR:: $\Omega$ ) background was comparable with that observed in the wild-type strain (MacLean, 2008). Thus, PcaR is not required for the regulation of pcaM expression.

In separate experiments, we confirmed that supplying $p c a Q$ in trans is sufficient to allow protocatechuate-dependent $p c a M$ expression in a $p c a Q$ mutant (Table 4). Thus, cultures of S. meliloti RmP1811 ( $p c a Q:: \Omega$ pcaM::gfp+/ lacZ) containing the empty expression plasmid pTH1227 showed no induction of $\beta$-galactosidase activity upon addition of protocatechuate. In contrast, assays of cultures of S. meliloti RmP1811 containing plasmid pTH2454 expressing PcaQ with a hexahistidine tag showed a sixfold induction of $\beta$-galactosidase activity when grown in the presence of protocatechuate. These results indicate that the His-tagged PcaQ has the ability to regulate pcaM (a)

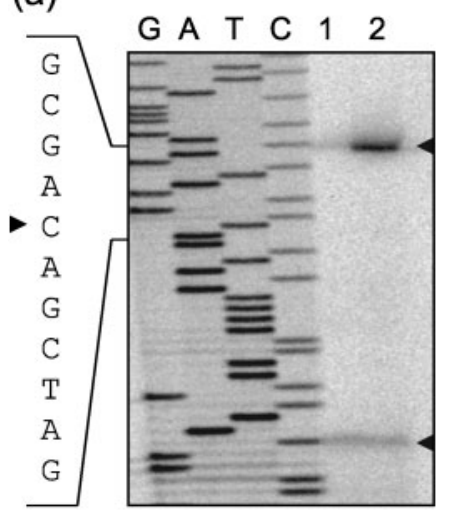

(c)

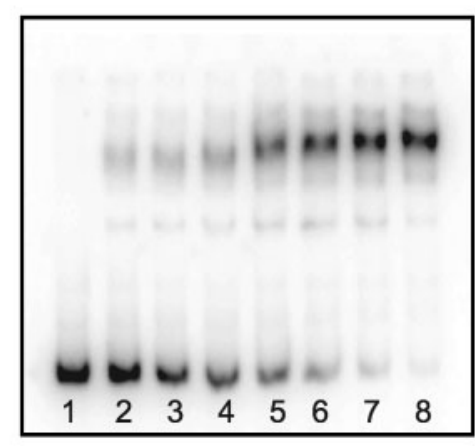

(b) PcaD CGTATAACCTCCTGGTTAAGGGAAGCCACGAAATATCATTTTACCTAA PCAM ACAATAACCGGGGATTATGGATTTCCGCCCATATTTCATTTTTGCATC

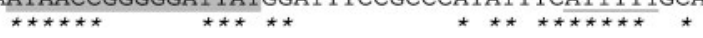

Fig. 2. Regulation of an $A B C$-type transport system encoded by pcaMNVWX. (a) Primer extension reactions were performed using mRNA isolated from $S$. meliloti wild-type strain RmP110 grown in the absence (lane 1) and presence (lane 2) of protocatechuate. Arrowheads (right) indicate the extension products obtained using two primers (results shown for one primer only), and an arrowhead (left) identifies the corresponding nucleotide. (b) Comparison of S. meliloti pcaD and pcaM regulatory regions (this work; MacLean et al., 2008). The -35 hexanucleotide region for each gene is underlined and the PcaO DNAbinding sites are shaded in grey. Invariant nucleotides are indicated by asterisks. (c) Electrophoretic mobility shift assay for PcaO binding to the intergenic region upstream of pcaM. A 246 bp radiolabelled probe (extending from -149 to +87 ; pcaM) was incubated in the presence of increasing concentrations of purified PcaO. Lanes 1-8 contained 0, 0.2, $0.5,1.2,2.5,4.9,12.4$ and $24.7 \mathrm{nM} \mathrm{PcaO}$. 
Table 3. Expression of pcaM: : gfp in S. meliloti

\begin{tabular}{|lccc|}
\hline Strain genotype & Gene fusion & \multicolumn{2}{c|}{ GFP fluorescence* (sD) } \\
\cline { 3 - 4 } & & Uninduced & Induced \\
\hline RmP110 & & & \\
$($ pTH2414) & $p c a M$ & $2443(69)$ & $15173(2663)$ \\
$($ pTH2276) & $p c a D$ & $1047(38)$ & $16115(572)$ \\
$($ pOT1) & None & $353(20)$ & $145(108)$ \\
RmP110 & & & \\
pcaQ:: $\Omega$ & & & \\
$($ pTH2414) & pcaM & $2204(198)$ & $1227(55)$ \\
$($ pTH2276) & pcaD & $422(99)$ & $208(102)$ \\
$($ pOT1 $)$ & None & $298(54)$ & $512(112)$ \\
\hline
\end{tabular}

*Shown are means of assays performed in triplicate using S. meliloti strains subcultured into M9 minimal medium with $0.5 \%(\mathrm{v} / \mathrm{v})$ glycerol in the absence (uninduced) and presence (induced) of $5 \mathrm{mM}$ protocatechuate. Data are representative of three independent experiments. SD, Standard deviation of assays performed in triplicate.

expression in vivo, and that the presence of the $\mathrm{N}$-terminal tag does not interfere with PcaQ regulatory activity.

We performed electrophoretic mobility shift assays using purified PcaQ-His to directly examine whether PcaQ binds to the regulatory region upstream of $p c a M$. PcaQ was shown to bind labelled probe (extending from -149 to +87 , with respect to the transcriptional start site of $p c a M)$ in the absence of a co-inducing metabolite (Fig. 2c), consistent with previous reports describing the binding of this and other LysR proteins to DNA independently of a co-effector (Fisher et al., 1988; Schell \& Poser, 1989; Rothmel et al., 1991; Wang et al., 1992; MacLean et al., 2008). In contrast, PcaQ did not shift a probe consisting of the S. meliloti pcal$p c a R$ intergenic sequence, even when up to $50 \mathrm{ng}$ purified protein was included in a parallel assay (data not shown). As PcaQ does not regulate the expression of pcaI, we included

Table 4. Complementation of an $S$. meliloti pcaQ mutant by $\mathrm{PcaO}-\mathrm{His}$

\begin{tabular}{|lcc|}
\hline Strain & \multicolumn{2}{c|}{$\boldsymbol{\beta}$-Galactosidase activity ${ }^{\star}(\mathrm{SD})$} \\
\cline { 2 - 3 } & Uninduced & Induced \\
\hline $\begin{array}{c}\text { RmP1811 } \\
(\mathrm{pTH} 1227)\end{array}$ & $117(9)$ & $116(25)$ \\
$\begin{array}{c}\text { RmP1811 } \\
(\mathrm{pTH} 2454)\end{array}$ & $115(12)$ & $696(14)$ \\
\hline
\end{tabular}

${ }^{*}$ Shown in Miller units are means of assays performed in triplicate using S. meliloti strains subcultured into M9 minimal medium with $0.5 \%(\mathrm{v} / \mathrm{v})$ glycerol in the absence (uninduced) and presence (induced) of $5 \mathrm{mM}$ protocatechuate. Data are representative of three independent experiments. SD, Standard deviation of assays performed in triplicate. this probe as a control to demonstrate that the interaction between PcaQ and sequence upstream of pcaM is specific. Our assays therefore indicate that $\mathrm{PcaQ}$ is directly involved in regulating expression of the transporter gene through an interaction with a binding site located within the pcaMsmb20569 intergenic region.

\section{Mutagenesis of the predicted PcaQ DNA-binding site reveals a functional role}

We wished to determine whether the PcaQ DNA-binding site predicted by our in silico analyses was essential to the regulation of pcaM expression in response to growth with protocatechuate. We targeted six conserved positions within the predicted PcaQ DNA-binding site for mutagenesis, and determined whether each mutation affected the regulation of pcaM expression (Fig. 3). The introduction of mutations within five of the six nucleotides targeted for mutagenesis (as underlined: 5'-ATAACCGGGGGATTAT-3') abolished the protocatechuate-inducible expression that was observed in the wild-type regulatory sequence (Fig. 3, pTH2414). In four of these mutations (corresponding to plasmids pTH2427, pTH2428, pTH2432 and pTH2433), the nucleotide substitution decreased the fold-induction observed in protocatechuate-cultured cells, and it is likely that these mutations interfered with the ability of PcaQ to bind upstream of pcaM, based upon an analysis of the DNAbinding site associated with pcaD (MacLean et al., 2008). Substitution of an adenine with a cytosine at a position that invariably encodes a purine in all predicted DNA-binding motifs (5'-ATAACCGGGGGATTAT-3') did not exert a strong effect upon the regulated expression of pcaM (Fig. 3, pTH2425); however, substitution with a guanine at the same position almost doubled the level of induced pcaM expression (pTH2424).

Substitution of a cytosine at a position that is highly conserved amongst the PcaQ regulatory sites (5'ATAACCGGGGGATTAT-3'; pTH2426) elicited a level of $p c a M:: g f p$ expression that was greater than twofold that observed in uninduced cells carrying the wild-type regulatory sequence. Furthermore, expression of $p c a M:: g f p$ was comparable in cells grown in the presence and absence of protocatechuate when this substitution was made, and in $S$. meliloti strains with (RmP110) and without (RmP1676) $\mathrm{PcaQ}$, indicating that the elevated expression of pcaM was independent of PcaQ-mediated regulation. This constitutive expression might be attributed to the generation of an UP element, an AT-rich sequence upstream of a promoter that interacts with $\alpha$ CTD-RNAP (Ross et al., 1993). However, the position of the mutation $(-69)$ was farther upstream than might be expected to influence expression (typically -60 to -40 ), and the altered regulatory sequence did not exhibit a strong similarity to the consensus UP element (Estrem et al., 1999). In any case, the transversion of $C \rightarrow A$ within the context of the AT-rich PcaQ-binding site appeared to strengthen interactions with the RNAP in a manner that was independent of $\mathrm{PcaQ}$ activation. 


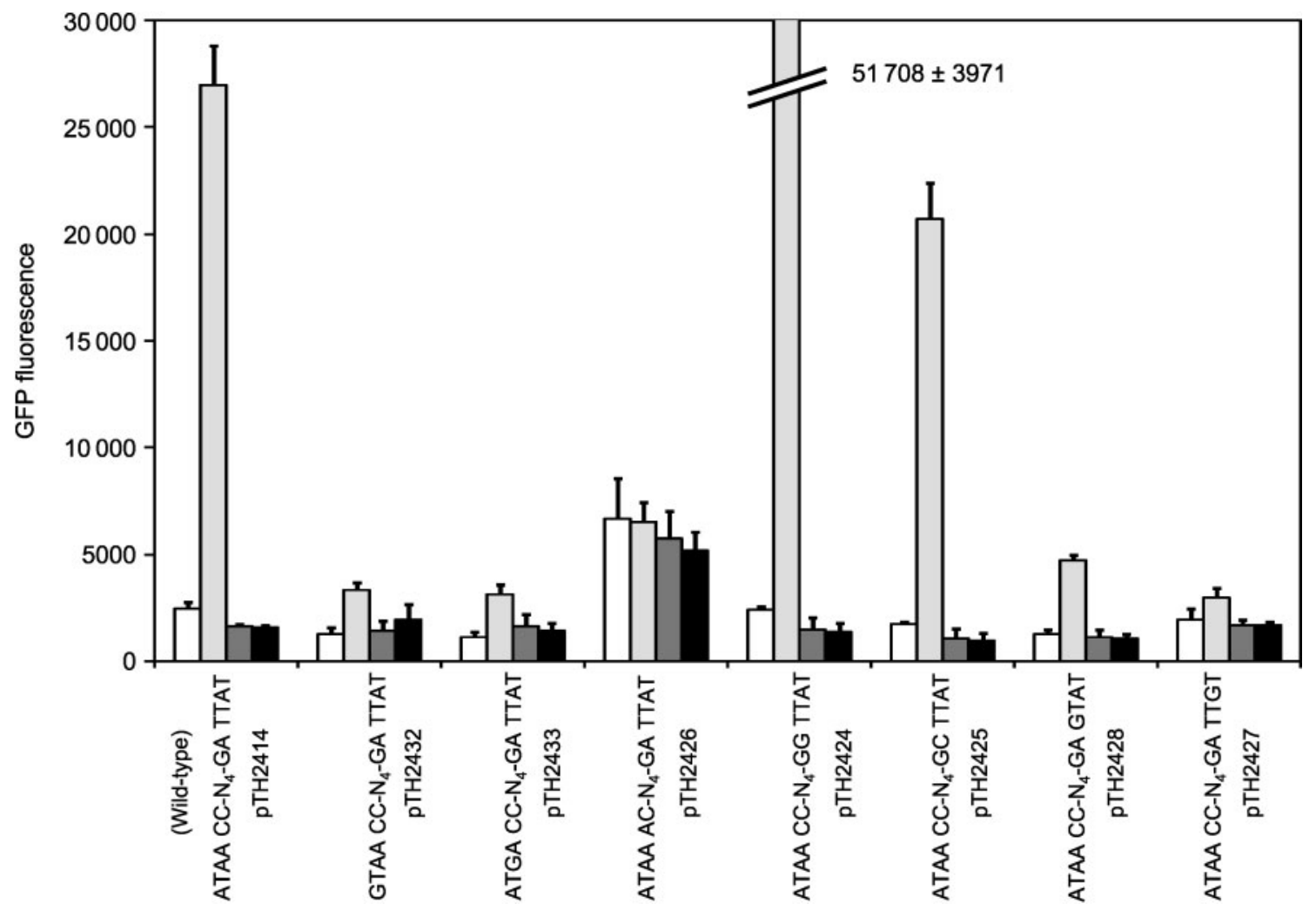

Fig. 3. Analysis of pcaM ::gfp expression in $S$. meliloti wild-type and $p c a Q:: \Omega$ strains. S. meliloti strains carrying plasmids as indicated were subcultured into M9 minimal medium with $0.5 \%(\mathrm{v} / \mathrm{v})$ glycerol with or without $5 \mathrm{mM}$ protocatechuate, and incubated at $30{ }^{\circ} \mathrm{C}$ for 4-6 h. Point mutations were introduced into a putative PcaQ DNA-binding site as shown, and assays were performed to assess the effect of mutagenesis upon the regulation of $p c a M$ expression. Reported is the mean expression as determined from three independent experiments; in each experiment, assays were performed in triplicate. Error bars, SD observed between experiments. White bars, S. meliloti RmP110 (wild-type), uninduced; light-grey bars, S. meliloti RmP110, induced; dark-grey bars, S. meliloti RmP1676 (RmP110 pcaQ:: $\Omega$ ), uninduced; black bars, S. meliloti RmP1676, induced.

\section{An ABC-type transport system is required for growth with protocatechuate in S. meliloti}

As a means of assessing whether the pcaMNVWX (smb20568-smb20784) cluster is involved in the uptake of protocatechuate, we constructed two mutant strains. $S$. meliloti strain RmP1710 ( $\mathrm{RmP} 110 \Delta p c a M)$ carries an inframe deletion of the gene encoding the periplasmic solutebinding protein $(p c a M)$ of the transporter, whereas RmP1712 (RmP110 pcaN:: $\Omega$ ) contains an antibioticresistance cassette within a permease gene (pcaN) (Fig. 4a). The S. meliloti mutants exhibited growth kinetics comparable with those of the wild-type strain (RmP110) when subcultured into minimal medium supplemented with succinate (Fig. 4b) or glycerol (data not shown). However, both transporter mutant strains grew poorly when cultured with protocatechuate as a sole carbon source, and did not grow as well as the wild-type strain in the presence of protocatechuate and succinate (Fig. 4c, d). The growth phenotype exhibited by RmP1710 and RmP1712 in the presence of protocatechuate was complemented by the cosmid pTH178 (MacLean, 2008), which carries the ABC-type transport system genes pcaMNVWX and the pcaDCHGB operon (MacLean et al., 2006). Strain RmG879 (Rm1021 pcaG::Tn5) is unable to metabolize protocatechuate (MacLean et al., 2006), and was included as a control in the growth assays. As expected, this strain grew well in the presence of succinate; however, it was unable to utilize protocatechuate as a sole source of carbon.

The data obtained from the growth curves (Fig. 4b-d) suggested that while the transporter mutants RmP1710 and RmP1712 grew poorly when offered protocatechuate as a sole carbon source, sufficient protocatechuate may enter the cell to permit some metabolism of the compound, which is best reflected by the growth of the transporter mutants (as compared with the $p c a G$ mutant) cultured in minimal medium with protocatechuate and succinate (Fig. 4c). We monitored the expression of $p c a I$ : : lac $Z$ in wild-type and transporter mutant strains of $S$. meliloti, and determined that expression was indeed induced by growth with protocatechuate in all three strains (Fig. 4e). Induction of pcaI expression requires the pathway metabolite $\beta$ ketoadipate, thus confirming passive diffusion or uptake via 
(a)
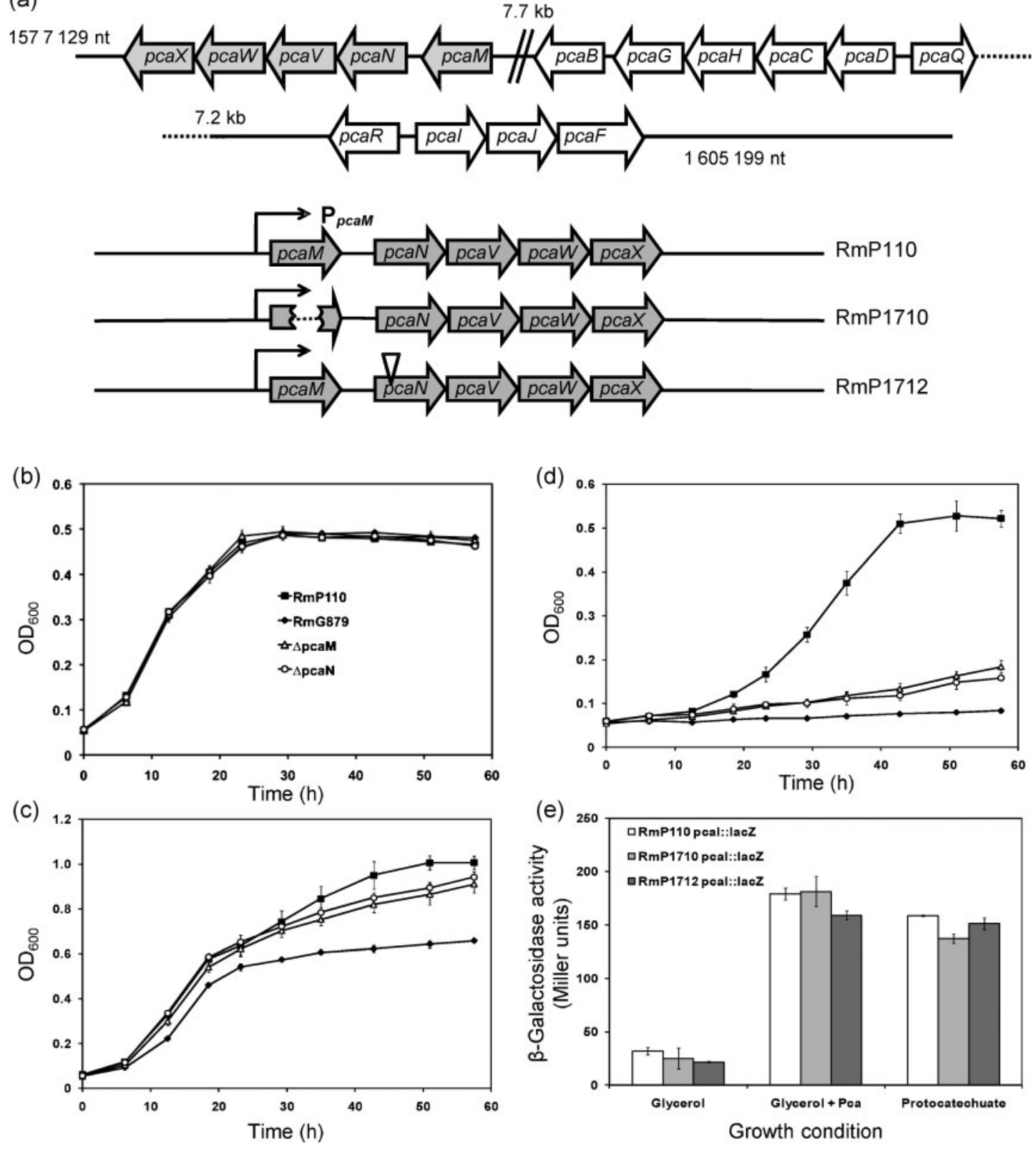

Fig. 4. (a) Schematic depiction of the S. meliloti protocatechuate transport and catabolic genes on the pSymB megaplasmid. pcaMNVWX (smb20568-smb20784) (shaded grey) encode a protocatechuate-inducible ABC-type transport system required for growth with protocatechuate (this work). (b-e) Growth of $S$. meliloti strains subcultured into M9 minimal medium with (b) $10 \mathrm{mM}$ succinate, (c) $10 \mathrm{mM}$ succinate and $5 \mathrm{mM}$ protocatechuate or (d) $5 \mathrm{mM}$ protocatechuate as sole carbon sources. Inoculum was from washed LBmc-grown cells and cultures were incubated with shaking at $30{ }^{\circ} \mathrm{C}$ for $57.5 \mathrm{~h}$; growth of each strain was assayed in triplicate cultures and the mean $\mathrm{OD}_{600}$ is shown; error bars, SD. (e) Expression of $p c a l::$ lac $Z$ was assayed in wild-type (RmP110) and transporter mutant backgrounds ( $\mathrm{RmP1710}$ and $\mathrm{RmP1712})$ in minimal medium with carbon sources as indicated; Pca, protocatechuate.

alternative transporter(s) of protocatechuate across the membrane (and subsequent metabolism) in the absence of the inducible transport system. Nonetheless, uptake in the pcaM and pcaN mutant strains is apparently not sufficient to support the growth of the transporter mutants in the absence of an additional carbon source.

\section{DISCUSSION}

The LysR-type protein PcaQ participates in the regulation of pcaD expression in S. meliloti and A. tumefaciens (Parke, 1993, 1996; MacLean et al., 2006, 2008), and we here report that expression of a gene encoding a component of an 
ABC-type transport system ( $p c a M)$ is likewise regulated by $\mathrm{PcaQ}$ in S. meliloti. Transport systems involved in the uptake of aromatic acids primarily belong to the major facilitator superfamily (MFS) of transporter proteins (Harwood et al., 1994; Collier et al., 1997; Williams \& Shaw, 1997; Leveau et al., 1998; D’Argenio et al., 1999; Chaudhry et al., 2007) and have been described predominantly in the $\gamma$-proteobacteria. Within the $\alpha$-proteobacteria, protocatechuate (and $p$-hydroxybenzoate) uptake has been described in $R$. leguminosarum, yet the genetic identity of the transport system has never been established (Wong et al., 1991). We show that the smb20568-smb20784 transport genes are required for growth with protocatechuate (Fig. 4), that expression of this system is protocatechuate-inducible (Table 3 ), and that it is subject to regulation by the $\beta$-ketoadipate regulatory protein $\mathrm{PcaQ}$ (Figs 2 and 3). We conclude that the system encoded by smb20568-smb20784 is a protocatechuate transport system, and propose that these genes be designated pcaMNVWX (Fig. 4a).

The organization of aromatic acid catabolic, regulatory and transport genes within supraoperons is well-documented (Harwood \& Parales, 1996), and we have furthermore observed that transport systems are often encoded near genes relevant to the catabolism of a substrate. We have identified PcaQ DNA-binding sites upstream of ABC-type transport systems in S. medicae, $R$. etli, R. leguminosarum, M. loti and Brucella species (Fig. 1, Table 2), and (as with $S$. meliloti) we note that these systems are located in close proximity to aromatic acid catabolic genes. ABC-type transport genes are also located near to the $p c a Q C H G$ gene cluster in the marine bacteria Roseobacter sp. MD193 (MED193_18204 to MED193_18229) and Phaeobacter gallaeciensis (RG210_05172 to RG210_05147), but appear to be absent in Roseobacter sp. GAI101, Ruegeria pomeroyi DSS-3, and related species (Buchan et al., 2004). Nonetheless, it seems likely that as a general rule, ABCtype transport systems mediate the uptake of protocatechuate and related aromatic acids in $\alpha$-proteobacteria, which represents a departure from the MFS-dominated systems characterized to date.

An interesting result from the in silico prediction of PcaQbinding sites was the identification of such motifs upstream of pcaHG in Pseudomonas, Ralstonia and Burkholderia (Fig. 1, Table 2). The genomes of these genera were selected for inclusion in our analyses based upon an annotation of the LysR-type protein PcaQ in the genome of at least one species from each group. While the presence of a $\mathrm{PcaQ}$ homologue in Pseudomonas has been noted (Overhage et al., 1999; Jiménez et al., 2002), there is currently no experimental evidence supporting the regulation of $p c a$ genes by $\mathrm{PcaQ}$ in these bacteria. In Acinetobacter baylyi, $p c a H G$ form part of a large operon ( $p c a I J F B D K C H G)$ that is regulated by the IclR-type regulatory protein $\mathrm{PcaU}$ (Gerischer et al., 1998). In contrast, expression of pcaDCHGB is modulated by $\mathrm{PcaQ}$ in S. meliloti and A. tumefaciens (Parke, 1993; MacLean et al., 2006), and we now offer in silico evidence that $\mathrm{PcaQ}$ may also regulate the expression of these genes in certain members of the $\beta$ - and $\gamma$-proteobacteria. We note that the binding sites identified in the $\beta$-proteobacteria atypically contain a $7 \mathrm{nt}$ spacer between the conserved left- and right-hand arms of the binding site; all other predicted sites encode $8 \mathrm{nt}$. Further study is required to confirm that PcaQ does regulate pcaHG expression in these species, and to determine what effect (if any) such a deletion might have upon the regulation of gene expression in Ralstonia and Burkholderia.

We have previously described the effect of introducing point mutations within a PcaQ DNA-binding site upstream of pcaD in S. meliloti (MacLean et al., 2008), and the identification of a second putative binding site upstream of pcaM presented an opportunity to expand upon our earlier analyses. Each of the six positions targeted for mutagenesis in this study (underlined) appears to be relevant to the regulation of pcaM expression (5'ATAACCGGGGGATTAT-3'), as replacement of any of these conserved nucleotides resulted in an altered expression of the transporter gene (Fig. 3). In addition, we note a general correlation between the degree of nucleotide conservation at a particular position and the severity of the regulatory phenotype upon mutagenesis. For example, the greatest effect upon the regulated expression of both $p c a D$ and pcaM was observed upon mutagenesis of $\mathrm{A}(-59) \mathrm{G}$, a position that is invariant in all $\mathrm{PcaQ}-$ binding sites predicted in this study (Fig. 1, Table 2).

Interestingly, the substitution of A(-62)G (5'-ATAACCGGGGGATTAT-3'; pTH2424) doubled the level of pcaM expression ( $>20$-fold induction) in response to the aromatic acid. It is worth emphasizing that this particular $\mathrm{A}(-62) \mathrm{G}$ mutation yields a dyad motif that more closely matches the majority of predicted DNA-binding sites [ $5^{\prime}$ ATAACY-(N) ${ }_{4}$-RGTTAW-3']. The pcaM sequence is one of only four predicted PcaQ DNA-binding sites to encode an adenine (as opposed to a guanine) at this position (Table 2 ), and each of these four sites is associated with an ABCtype transport system which presumably mediates the transport of protocatechuate (in R. etli, S. meliloti and $S$. medicae). In total, of the 11 predicted PcaQ DNA-binding sites positioned upstream of transport genes, 10 contain nucleotide substitutions or deletions that likely reduce the level of gene expression under inducing conditions (Table 2, bold type), based upon mutagenesis of comparable positions in sites upstream of pcaD (MacLean et al., 2008) or pcaM (this study). In comparison, we note that no such mutations are present within binding sites associated with the catabolic genes ( $p c a D C H G B$ and $p c a H G$ ). The functional significance of encoding transport systems with a decreased responsiveness to protocatechuate (in terms of gene expression) imparts an interesting physiological consequence. Protocatechuate (and particularly the metabolite $\beta$-carboxy-cis,cis-muconate) is toxic if allowed to accumulate intracellularly (Parke et al., 2000), and a highly expressed aromatic acid transport system may be 
maladaptive in an environment rich in protocatechuate and related compounds, particularly if the transport system has a high affinity for its substrate. For example, it has been proposed that a mutational hotspot in the protocatechuate uptake system vanK of Acinetobacter baylyi may enhance the adaptability of this species in a soil environment by providing a subset of the population with a decreased ability to transport protocatechuate and thus a greater resistance to protocatechuate exposure (D'Argenio et al., 1999; Parke et al., 2000). It is interesting to speculate that the preferential accumulation of mutations within $\mathrm{PcaQ}$ DNA-binding sites upstream of transport genes may reflect an adaptation to limit the active import of protocatechuate into the cell by limiting the expression of a relevant transport system. Alternatively, it is possible that the absence of such mutations in sites associated with pca catabolic genes may be due to stronger selective pressure acting against systems in which the expression of these (catabolic) genes is compromised. Indeed, these alternative scenarios are not mutually exclusive.

\section{ACKNOWLEDGEMENTS}

This work was supported by funding from the Natural Sciences and Engineering Research Council of Canada. We thank Catharine White for helpful comments and advice on the manuscript.

\section{REFERENCES}

Akakura, R. \& Winans, S. C. (2002). Mutations in the occQ operator that decrease OccR-induced DNA bending do not cause constitutive promoter activity. J Biol Chem 277, 15773-15780.

Allaway, D., Schofield, N. A., Leonard, M. E., Gilardoni, L., Finan, T. M. \& Poole, P. S. (2001). Use of differential fluorescence induction and optical trapping to isolate environmentally induced genes. Environ Microbiol 3, 397-406.

Buchan, A., Neidle, E. L. \& Moran, M. A. (2004). Diverse organization of genes of the $\beta$-ketoadipate pathway in members of the marine Roseobacter lineage. Appl Environ Microbiol 70, 1658-1668.

Bundy, B. M., Collier, L. S., Hoover, T. R. \& Neidle, E. L. (2002). Synergistic transcriptional activation by one regulatory protein in response to two metabolites. Proc Natl Acad Sci U S A 99, 7693-7698.

Chaudhry, M. T., Huang, Y., Shen, X. H., Poetsch, A., Jiang, C. Y. \& Liu, S. J. (2007). Genome-wide investigation of aromatic acid transporters in Corynebacterium glutamicum. Microbiology 153, 857-865.

Chugani, S. A., Parsek, M. R., Hershberger, C. D., Murakami, K., Ishihama, A. \& Chakrabarty, A. M. (1997). Activation of the catBCA promoter: probing the interaction of CatR and RNA polymerase through in vitro transcription. J Bacteriol 179, 2221-2227.

Collier, L. S., Nichols, N. N. \& Neidle, E. L. (1997). benK encodes a hydrophobic permease-like protein involved in benzoate degradation by Acinetobacter sp. strain ADP1. J Bacteriol 179, 5943-5946.

Cowie, A., Cheng, J., Sibley, C. D., Fong, Y., Zaheer, R., Patten, C. L., Morton, R. M., Golding, G. B. \& Finan, T. M. (2006). An integrated approach to functional genomics: construction of a novel reporter gene fusion library for Sinorhizobium meliloti. Appl Environ Microbiol 72, 7156-7167.

Crooks, G. E., Hon, G., Chandonia, J. M. \& Brenner, S. E. (2004). WebLogo: a sequence logo generator. Genome Res 14, 1188-1190.
D’Argenio, D. A., Segura, A., Coco, W. M., Bünz, P. V. \& Ornston, L. N. (1999). The physiological contribution of Acinetobacter PcaK, a transport system that acts upon protocatechuate, can be masked by the overlapping specificity of VanK. J Bacteriol 181, 3505-3515.

Estrem, S. T., Ross, W., Gaal, T., Chen, Z. W., Niu, W., Ebright, R. H. \& Gourse, R. L. (1999). Bacterial promoter architecture: subsite structure of UP elements and interactions with the carboxy-terminal domain of the RNA polymerase $\alpha$ subunit. Genes Dev 13, 2134-2147.

Finan, T. M., Kunkel, B., De Vos, G. F. \& Signer, E. R. (1986). Second symbiotic megaplasmid in Rhizobium meliloti carrying exopolysaccharide and thiamine synthesis genes. J Bacteriol 167, 66-72.

Fisher, R. F., Egelhoff, T. T., Mulligan, J. T. \& Long, S. R. (1988). Specific binding of proteins from Rhizobium meliloti cell-free extracts containing NodD to DNA sequences upstream of inducible nodulation genes. Genes Dev 2, 282-293.

Fritsch, P. S., Urbanowski, M. L. \& Stauffer, G. V. (2000). Role of the RNA polymerase $\alpha$ subunits in MetR-dependent activation of metE and $m e t H$ : important residues in the C-terminal domain and orientation requirements within RNA polymerase. J Bacteriol 182, 5539-5550.

Gerischer, U., Segura, A. \& Ornston, L. N. (1998). PcaU, a transcriptional activator of genes for protocatechuate utilization in Acinetobacter. J Bacteriol 180, 1512-1524.

Goethals, K., Van Montagu, M. \& Holsters, M. (1992). Conserved motifs in a divergent nod box of Azorhizobium caulinodans ORS571 reveal a common structure in promoters regulated by LysR-type proteins. Proc Natl Acad Sci U S A 89, 1646-1650.

Harwood, C. S. \& Parales, R. E. (1996). The $\beta$-ketoadipate pathway and the biology of self-identity. Annu Rev Microbiol 50, 553-590.

Harwood, C. S., Nichols, N. N., Kim, M. K., Ditty, J. L. \& Parales, R. E. (1994). Identification of the pcaRKF gene cluster from Pseudomonas putida: involvement in chemotaxis, biodegradation, and transport of 4-hydroxybenzoate. J Bacteriol 176, 6479-6488.

Huang, J. Z. \& Schell, M. A. (1991). In vivo interactions of the NahR transcriptional activator with its target sequences. Inducer-mediated changes resulting in transcription activation. J Biol Chem 266, 1083010838.

Jiménez, J. I., Miñambres, B., García, J. L. \& Díaz, E. (2002). Genomic analysis of the aromatic catabolic pathways from Pseudomonas putida KT2440. Environ Microbiol 4, 824-841.

Ledger, T., Aceituno, F. \& González, B. (2009). 3-Chlorobenzoate is taken up by a chromosomally encoded transport system in Cupriavidus necator JMP134. Microbiology 155, 2757-2765.

Leveau, J. H., Zehnder, A. J. \& van der Meer, J. R. (1998). The $t f d K$ gene product facilitates uptake of 2,4-dichlorophenoxyacetate by Ralstonia eutropha JMP134(pJP4). J Bacteriol 180, 2237-2243.

MacLean, A. M. (2008). Study of saprophytic competence in Sinorhizobium meliloti. PhD thesis, McMaster University, Hamilton, ON, Canada.

MacLean, A. M., MacPherson, G., Aneja, P. \& Finan, T. M. (2006). Characterization of the $\beta$-ketoadipate pathway in Sinorhizobium meliloti. Appl Environ Microbiol 72, 5403-5413.

MacLean, A. M., Anstey, M. I. \& Finan, T. M. (2008). Binding site determinants for the LysR-type transcriptional regulator PcaQ in the legume endosymbiont Sinorhizobium meliloti. J Bacteriol 190, 1237-1246.

MacLellan, S. R., Smallbone, L. A., Sibley, C. D. \& Finan, T. M. (2005). The expression of a novel antisense gene mediates incompatibility within the large repABC family of $\alpha$-proteobacterial plasmids. Mol Microbiol 55, 611-623.

Maddocks, S. E. \& Oyston, P. C. (2008). Structure and function of the LysR-type transcriptional regulator (LTTR) family proteins. Microbiology 154, 3609-3623. 
Mauchline, T. H., Fowler, J. E., East, A. K., Sartor, A. L., Zaheer, R., Hosie, A. H., Poole, P. S. \& Finan, T. M. (2006). Mapping the Sinorhizobium meliloti 1021 solute-binding protein-dependent transportome. Proc Natl Acad Sci U S A 103, 17933-17938.

McFall, S. M., Chugani, S. A. \& Chakrabarty, A. M. (1998). Transcriptional activation of the catechol and chlorocatechol operons: variations on a theme. Gene 223, 257-267.

Nichols, N. N. \& Harwood, C. S. (1997). PcaK, a high-affinity permease for the aromatic compounds 4-hydroxybenzoate and protocatechuate from Pseudomonas putida. J Bacteriol 179, 5056-5061.

Oke, V. \& Long, S. R. (1999). Bacterial genes induced within the nodule during the Rhizobium-legume symbiosis. Mol Microbiol 32, 837-849.

Overhage, J., Kresse, A. U., Priefert, H., Sommer, H., Krammer, G., Rabenhorst, J. \& Steinbüchel, A. (1999). Molecular characterization of the genes $p c a G$ and pcaH, encoding protocatechuate 3,4dioxygenase, which are essential for vanillin catabolism in Pseudomonas sp. strain HR199. Appl Environ Microbiol 65, 951-960.

Park, W., Jeon, C. O. \& Madsen, E. L. (2002). Interaction of NahR, a LysR-type transcriptional regulator, with the alpha subunit of RNA polymerase in the naphthalene degrading bacterium, Pseudomonas putida NCIB 9816-4. FEMS Microbiol Lett 213, 159-165.

Parke, D. (1993). Positive regulation of phenolic catabolism in Agrobacterium tumefaciens by the $p c a Q$ gene in response to $\beta$ carboxy-cis,cis-muconate. J Bacteriol 175, 3529-3535.

Parke, D. (1996). Characterization of PcaQ, a LysR-type transcriptional activator required for catabolism of phenolic compounds, from Agrobacterium tumefaciens. J Bacteriol 178, 266-272.

Parke, D., D’Argenio, D. A. \& Ornston, L. N. (2000). Bacteria are not what they eat: that is why they are so diverse. J Bacteriol 182, 257-263.

Parsek, M. R., Shinabarger, D. L., Rothmel, R. K. \& Chakrabarty, A. M. (1992). Roles of CatR and cis,cis-muconate in activation of the catBC operon, which is involved in benzoate degradation in Pseudomonas putida. J Bacteriol 174, 7798-7806.

Prentki, P. \& Krisch, H. M. (1984). In vitro insertional mutagenesis with a selectable DNA fragment. Gene 29, 303-313.
Quandt, J. \& Hynes, M. F. (1993). Versatile suicide vectors which allow direct selection for gene replacement in Gram-negative bacteria. Gene 127, 15-21.

Ross, W., Gosink, K. K., Salomon, J., Igarashi, K., Zou, C., Ishihama, A., Severinov, K. \& Gourse, R. L. (1993). A third recognition element in bacterial promoters: DNA binding by the alpha subunit of RNA polymerase. Science 262, 1407-1413.

Rothmel, R. K., Shinabarger, D. L., Parsek, M. R., Aldrich, T. L. \& Chakrabarty, A. M. (1991). Functional analysis of the Pseudomonas putida regulatory protein CatR: transcriptional studies and determination of the CatR DNA-binding site by hydroxyl-radical footprinting. J Bacteriol 173, 4717-4724.

Schell, M. A. \& Poser, E. F. (1989). Demonstration, characterization, and mutational analysis of NahR protein binding to nah and sal promoters. J Bacteriol 171, 837-846.

Stanier, R. Y. \& Ingraham, J. L. (1954). Protocatechuic acid oxidase. J Biol Chem 210, 799-808.

Tao, K., Fujita, N. \& Ishihama, A. (1993). Involvement of the RNA polymerase $\alpha$ subunit C-terminal region in co-operative interaction and transcriptional activation with OxyR protein. Mol Microbiol 7, 859-864.

Wang, L., Helmann, J. D. \& Winans, S. C. (1992). The A. tumefaciens transcriptional activator OccR causes a bend at a target promoter, which is partially relaxed by a plant tumor metabolite. Cell 69, 659-667.

Williams, P. A. \& Shaw, L. E. (1997). mucK, a gene in Acinetobacter calcoaceticus ADP1 (BD413), encodes the ability to grow on exogenous cis,cis-muconate as the sole carbon source. J Bacteriol 179, 5935-5942.

Wong, C. M., Dilworth, M. J. \& Glenn, A. R. (1991). Evidence for two uptake systems in Rhizobium leguminosarum for hydroxyl-aromatic compounds metabolized by the 3-oxoadipate pathway. Arch Microbiol 156, 385-391.

Yuan, Z. C., Zaheer, R. \& Finan, T. M. (2006). Regulation and properties of PstSCAB, a high-affinity, high-velocity phosphate transport system of Sinorhizobium meliloti. J Bacteriol 188, 1089-1102.

Edited by: D. J. Arp 